\title{
The Effect of Simvastatin on Sodium Dichromate-Induced Oxidative Stress
}

\author{
Zahra Goodarzi ${ }^{1}$; Esmaeil Karami ${ }^{1}$; Massumeh Ahmadizadeh ${ }^{1,2,{ }^{*}}$; Kambiz Ahmadi Angali ${ }^{3}$ \\ ${ }_{1}^{1}$ Department of Occupational Health, Engineering, School of Health, Ahvaz Jundishapur University of Medical Sciences, Ahvaz, IR Iran \\ ${ }_{2}^{2}$ Physiology Research Center, Ahvaz Jundishapur University of Medical Sciences, Ahvaz, IR Iran \\ ${ }^{3}$ Department of Statistics and Epidemiology, School of Health, Ahvaz Jundishapur University of Medical Sciences .Ahvaz, IR Iran \\ ${ }^{*}$ Corresponding author: Massumeh Ahmadizadeh, Physiology Research Center, Ahvaz Jundishapur University of Medical Sciences, Ahvaz, IR Iran. Tel: +98-6113738269, Fax: +98- \\ 6113738282, E-mail: ahmadizadeh_m@ajums.ac.ir
}

Received: April 21, 2014; Revised: June 29, 2014; Accepted: June 29, 2014

\begin{abstract}
Background: Hexavalent Chromium (CrVI) is used for various industrial applications. This chemical agent can cause inflammation and induce numerous human diseases, including severe damage to the liver and lung. Simvastatin(SIMV) is widely clinically used for lowering hypercholesterolemia. This agent also has anti-inflammatory, anti-oxidant, and anti-thrombotic effects.

Objectives: The aim of the present study was to investigate the role of SIMV on sodium dichromate (Cr VI)-induced oxidative stress in rat. Materials and Methods: Sixty-four adult male Wistar rats (180-220 g weight) were randomly assigned to eight groups $(\mathrm{n}=8)$. Group one received SIMV $20 \mathrm{mg} / \mathrm{kg} /$ day. Group two was given vehicle only. Groups three, five and seven received intraperitoneally (i.p) sodium dichromate at doses of 8,12 and $16 \mathrm{mg} / \mathrm{kg}$ BW (Body Weight) for eight consecutive days, respectively. Groups four, six and eight pretreated with the $20 \mathrm{mg} / \mathrm{kg}$ SIMV 30 minutes to prior administration of sodium dichromate in a doses of 8,12 and $16 \mathrm{mg} / \mathrm{kg}$, respectively. The experiment repeated for eight consecutive days. Twenty-four hours after the last administration, animals were killed with overdose of sodium pentobarbital. Blood was collected for determination of malondialdehyd (MDA) and glutathione (GSH) levels.

Results: The level of GSH significantly decreased. In contrast, the plasma level of MDA significantly increased in a dose dependent manner in CrVI-treated rats, when compared to control animals. SIMV had no effect on the biochemical parameters when compared to control rats, but significantly increased GSH concentration and decreased MDA level in CrVI-treated rats.

Conclusions: This finding suggests that SIMV may have a protective effect against CrVI-induced oxidative stress.
\end{abstract}

Keywords:Simvastatin; Sodium Dichromate; Oxidative Stress; Glutathione; RAT

\section{Background}

Chromium compounds are widely used in industrial and chemical processes such as tannery, stainless steel manufacturing, welding, paint and pigment producing, metal finishing, and wood preservation (1). Occupational exposure to hexavalent chromium induced adverse effects on health and also chromium compounds are highly toxic and induced dermatotoxicity, immunotoxicity, neurotoxicity, genotoxicity, carcinogenicity and nephrotoxicity $(1,2)$. Hexavalent chromium compounds include ammonium chromate, calcium chromate, potassium chromate, potassium dichromate, and sodium chromate can generate reactive oxygen species (ROS) during its reduction in successive oxidation states, which are well known to produce toxic effects and excessive quantity of ROS generated by this reaction. Reactive oxygen species can cause injury to cellular proteins, lipids, and DNA leading to astute known as oxidative stress $(3,4)$. In fact, hexavalent chromium is rapidly reduced by extracellular body fluids (such as saliva, gastric juice and epitheliallining fluid, and in nontarget cells including pulmonary alveolar macrophages and red blood cells) to inactive chromium III (4-9).

Chromium hexavalent can be reduced by biological reductants including glutathione, cycteine, ascorbate, hydrogen and flavor enzymes such as glutathione reductase and selectively inhibit the activity of glutathione reductase (10). Hexavalent chromium can permeate into red blood cells and bound with hemoglobin and lymphocytes, and stay longer in the body; therefore, it may provide a marker of long-term exposure. A little is known about chromium uptake in white blood cells (WBC) (11, 12). On the other hand, administration of hexavalent chromium to rat caused severe progressive proteinuria, urea nitrogen, and creatinine, as well as elevation in serum alanine aminotransferase activity and hepatic lipid peroxide formation (13).

Chromium - particularly in the hexavalent form - is considered to have sever toxicity and long-time-exposed individuals can develop tissue necrosis (14). The adverse effects of ROS are balanced by the antioxidant action of non-enzymatic antioxidants in addition to antioxidant enzymes. The role of oxidative stress in injury associated with hexavalent chromium exposure suggests that antioxidant supplementation may mitigate chromateinduced toxicity (15). Statin compounds reduce inflammation by taking action in many cells (16) and HMG CoA

Copyright (C) 2014, Ahvaz Jundishapur University of Medical Sciences. This is an open-access article distributed under the terms of the Creative Commons Attribution-NonCommercial 4.0 International License (http://creativecommons.org/licenses/by-nc/4.0/) which permits copy and redistribute the material just in noncommercial usages, provided the original work is properly cited. 
reductase inhibitors (statins) promote reduction in plasma levels of low-density lipoprotein (LDL) cholesterol (1720) and it is also suggested that statins promote systemic antioxidant effects through the suppression of distinct oxidation pathways.

\section{Objectives}

This study aims to assess the effect of simvastatin on chromium hexavalent induced oxidative stress in rats.

\section{Materials and Methods}

Adult male Wistar rats (180-220 g) were housed in groups of three in clear polypropylene cages in a light cycle (12 hours light and 12 hours dark). The animals were kept at temprature of $23 \pm 2$ centigrade, fed with pellet rat diet and tap water. Rats were divided randomly into eight groups. The study groups were assigned the following regimens:

Group one: rats were treated (oral gavage) with SIMV at dose of $20 \mathrm{mg} / \mathrm{kg} \mathrm{BW/day,} \mathrm{for} 12$ days. Group two: used as controls (given vehicle, normal saline). Groups three, five and seven were received intraperitoneal (ip) sodium dichromate at doses of 8,12 and $16 \mathrm{mg} / \mathrm{kg} \mathrm{BW} /$ day for eight consecutive days, respectively. Groups four, six and eight were pretreated with SIMV (20 mg/kg BW, oral gavage) four days prior to administration of sodium dichromate $(8,12$ and $16 \mathrm{mg} / \mathrm{kg} \mathrm{BW} /$ day $)$ for eight consecutive days, respectively. Twenty-four hours after the last treatment, all rats were killed with overdose of sodium pentobarbital. Bloods was collected for determination of malondialdehyd (MDA) and glutathione (GSH) levels.

\subsection{Determination of Lipid Peroxidation}

Lipid peroxidation in blood was estimated calorimetrically by measuring thiobarbituric acid reactive substances (TBARS) by, Ogungbenro and Yagi $(21,22)$.

\subsection{Preparation of Plasma}

Blood samples with EDTA were centrifuged at 4000 $\mathrm{rpm}$ for five minutes. Plasma was collected for analyses (23). Then, $1 \mathrm{~mL}$ plasma were collected into a $10 \mathrm{~mL}$ tube and $2 \mathrm{~mL}$ of thiobarbituric acid reagent was added. The tubes placed in vortex-mix for 10 seconds and then in boiling water bath $\left(90-100^{\circ} \mathrm{C}\right)$ for 20 minutes. After seven minutes, the resulting supernatant was removed and measured at wave of $532 \mathrm{~nm}$ with the use of SERIEC-7000 spectrophotometer. Malondialdehyd concentration was determined by using 1,1,3,3-tetraethoxypropane as external standard (0.5-2.5 $\mu \mathrm{M})$.

\subsection{Estimation of Plasma Level of Reduced Gluta- thione}

The GSH concentration was measured with DTNB by Ellman's Method (24). For measurement of plasma
GSH, $2.3 \mathrm{~mL}$ of potassium phosphate buffer $0.2 \mathrm{M}$ with $\mathrm{pH}=7.6$ was taken in the test tube and $0.2 \mathrm{~mL}$ plasma was added. Then, $0.5 \mathrm{~mL}$ DTNB $0.001 \mathrm{M}$ was added to the plasma solution. An absorbance of reaction product in the cuvette was read after five minute at fixed wave of $412 \mathrm{~nm}$ with the same spectrophotometer and GSH level was determined and 0.2-0.8 $\mathrm{mM}$ solutions were prepared from $1 \mathrm{mM}$ GSH stock solution for drawing standard curve (Figure 1).

\subsection{Statistical Analysis}

The data were analyzed using SPSS 16.0. Data were analyzed by using One-way analysis of variance (ANOVA), followed by post hoc analysis with LSD test. Probability value of $\leq 0.05$ was determined to be statistically significant.

\section{Results}

\subsection{Lipid per Oxidation (MDA) Level of Plasma}

Standard curve of MDA was obtained as shown in Figure 2 , and the level of lipid peroxides was expressed as $\mu$ mole of MDA (21, 22). Concentration of MDA in the plasma was significantly increased in dose dependent manner in the chromium treated animals when compared to the control group (Figure 3). However, pretreated rats with 20 $\mathrm{mg} / \mathrm{kg} /$ day of SIMV significantly $(\mathrm{P} \leq 0.05)$ decreased the level of MDA in chromium treated animals, when compared to group that pretreated with vehicle (Figure 3 ).

\subsection{Estimation of Plasma Concentration of Re- duced Glutathione}

Standard curve of GSH was obtained as shown in Figure 1 , and the level of GSH was expressed as $\mu$ mole of GSH. Concentrations of GSH in the plasma in chromium-treated group were significantly decreased when compared to the control value. However, administration of single dose of SIMV $(20 \mathrm{mg} / \mathrm{kg} /$ day $)$ significantly $(\mathrm{P} \leq 0.05)$ increased the level of GSH in chromium-treated rats when compared to non-pretreated rats (Figure 4).

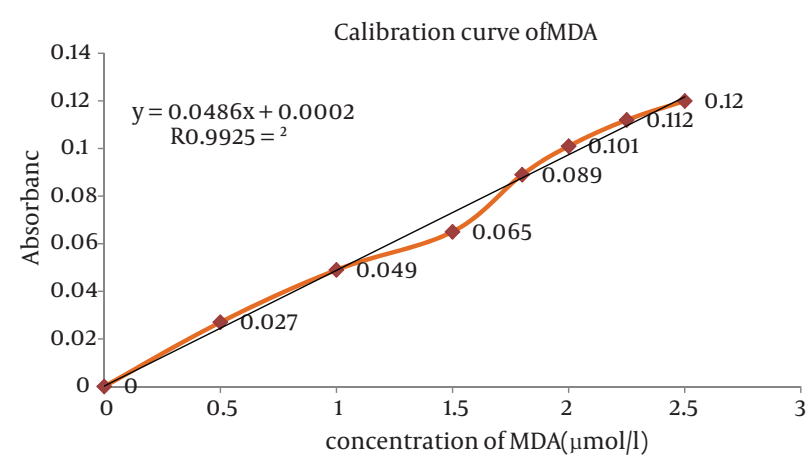

Figure 1. Standard Curve for Glutathione (GSH) 


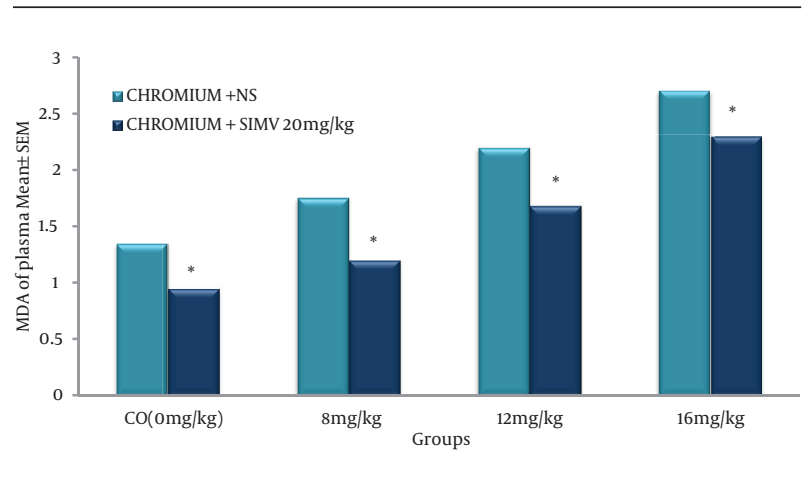

Figure 2. Standard Curve for Malondialdehyd (MDA)

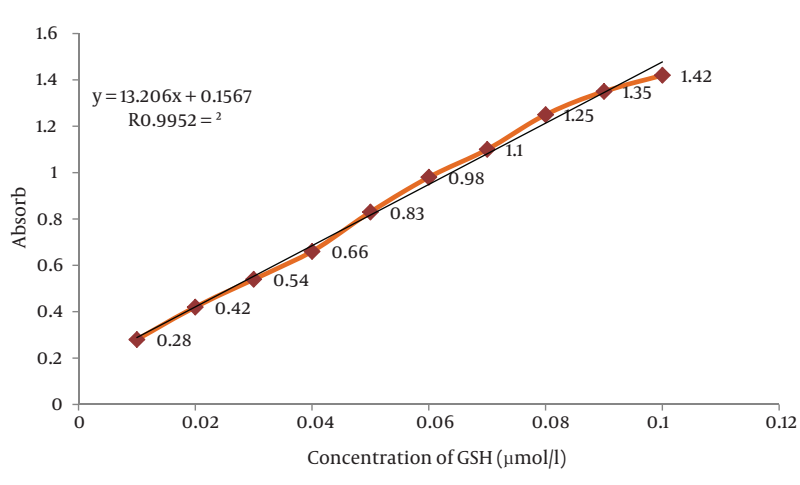

Figure 3. Effect of Simvastatin on MDA Level in Rat Plasma Treated With Chromium at Doses of $0,8,12$ or $16 \mathrm{mg} / \mathrm{kg}$. Difference is Significant ( $\mathrm{P} \leq$ $0.05)$

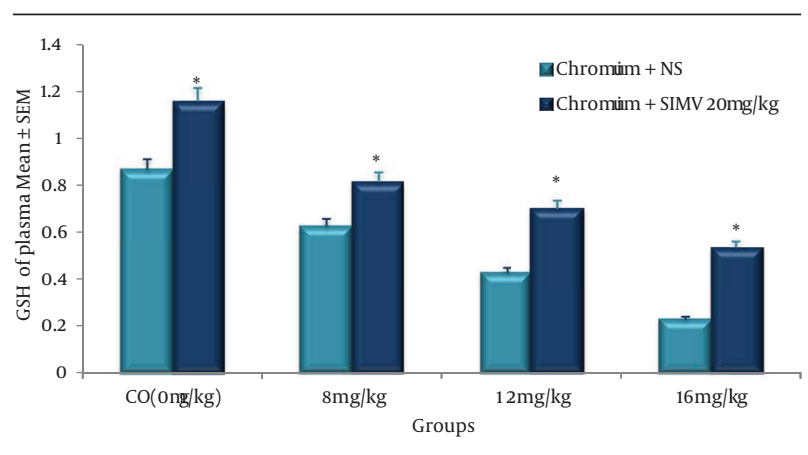

Figure 4. Effect of Simvastatin on GSH Level in Rat Plasma Treated With Chromium at Doses of $0,8,12$ or $16 \mathrm{mg} / \mathrm{kg}$. Difference is significant ( $\mathrm{P} \leq$ $0.05)$

\section{Discussion}

The results of the present study indicated that the level of GSH significantly $(P \leq 0.05)$ decreased in rats treated with various doses of chromium VI when compared to those in control group. The depletion of GSH was noted in a dose-dependent manner. Curello et al. found that Plasma GSH plays a crucial role in the detoxification processes of electrophonilic metabolites of xenobiotic and oxygen free radicals, such that release of reduced and oxi- dized glutathione into the plasma is considered as a reliable index of oxidative stress (24). Mohamed and Saber showed that injection of potassium dichromate, subcutaneously, cause GSH depletion (2). Our findings show that ip injection of various doses of sodium dichromate significantly ( $P \leq 0.05)$ increased MDA levels in rats plasma when compared to non-treated animals (control).similarly, Sai Ram et al. expressed that Chromate significantly enhanced plasma and tissue MDA levels (25). Geetha et al. reported that chromium 6-induced oxidative stress in rat serum (26). Arivarasu et al. found that potassium dichromate produced oxidative stress in rat small intestine of rat (27). Ogungbenro found that $\mathrm{K}_{2} \mathrm{Cr}_{2} \mathrm{O}_{7}$ significantly $(\mathrm{P} \leq 0.05)$ enhances oxidative stress and the course of apoptosis, possibly through oxidative stress and mitochondrial damage (21). Soudani et al. concluded that exposure of rats to chromium, promoted oxidative stress with an increase in MDA and a decrease in glutathione (GSH) levels and also a decrease in antioxidant nonenzymatic levels such as glutathione, nonprotein thiol and vitamin C (28). Although the mode of action Chromium VI (CrVI)-induced toxicity is not completely understood, but sufficient evidence demonstrated that it may be related to oxidative stress including reduction of the level of GSH.

SIMV is widely used clinically for lowering hypercholesterolemia and this chemical agent has significant effects on numerous measures of inflammation, immunity and oxidative stress $(28,29)$. The present data indicates that the daily oral gavage of $20 \mathrm{mg} / \mathrm{kg}$ SIMV reduced the level of plasma oxidative stress, especially in groups received high dose of CrVI. It has been suggested that statins possess antioxidant properties by increasing the NO bioavailability, reducing lipid peroxidation and ROS production (30-32). The results of the present study indicated that SIMV ameliorates chromium toxicity as indicated by elevation of GSH level and depleted lipid peroxidation, when compared to those pretreated with vehicle. Maheshwari et al. Found that statins reduced cisplatininduced nephrotoxicity in rats (32). Similarly, Jabbari et al. reported that SIMV protected rat kidney against gentamicin-induced nephrotoxicity (33). Fouad et al. reported that SIMV is one of the antioxidatve drugs, which have SIMV treatment ameliorates injury of rat testes induced by cadmium toxicity (34). Stoll et al. expressed that antioxidant effects of statins likely contribute to their clinical efficacy in treating cardiovascular disease as well as other chronic conditions associated with increase of oxidative stress in humans (35). Ramanjaneyulu et al. observed that that atorvastatin offers a significant protection against DOX-induced oxidative stress and DNA damage in the heart and testes of mice (36).

The results of the present study demonstrate that SIMV at a concentration of $20 \mathrm{mg} / \mathrm{kg}$ protected the animals significantly ( $\mathrm{P} \leq 0.05)$ from the chromium induced oxidative damage. The present study supports the view that statins not only protected drugs induced oxidative stress, 
but also may be useful against oxidative stress induced by industrial chemicals.

In conclusion, CrVI produced dose-dependent toxicity and SIMV had potential to ameliorate CrVI toxicity by its antioxidant property.

\section{Acknowledgements}

The source of data used in this paper was extracted from the master thesis of Zahra Goodarzi, student of Occupational Health engineering Department, School of Health, Ahvaz Jundishapur University of Medical Sciences, Ahvaz, Iran.

\section{Authors' contributions}

Zahra Goodarzi was responsible for doing the project (related to her MSc thesis); Esmaeil Karami was technical assistance; Massumeh Ahmadizadeh, supervised the project; Kambiz Ahmadi Angali was responsible for data analyses.

\section{Funding/Support}

This study was supported by physiology research center and the research deputy of Ahvaz Jundishapur University of Medical Sciences (Grant NO.PRC-151).

\section{References}

1. Quinteros FA, Poliandri AH, Machiavelli LI, Cabilla JP, Duvilanski $\mathrm{BH}$. In vivo and in vitro effects of chromium VI on anterior pituitary hormone release and cell viability. Toxicol Appl Pharmacol. 2007;218(1):79-87.

2. Mohamed NE, Saber RA. Effect of aqueous extract of damsissa (Ambrosia maritima) on the biochemical changes induced by potassium dichromate in rats. JAm Sci. 2011;7(3):234-42.

3. Acharya UR, Mishra M, Mishra I. Status of antioxidant defense system in chromium-induced Swiss mice tissues. EnvironmToxicol Pharmacol. 2004;17(3):117-23.

4. De Flora S, Camoirano A, Bagnasco M, Zanacchi P. Chromium and carcinogenesis. In: Berthon G editor. Handbook of Metal-Ligand Interactions in Biological Fluids: Bioinorganic Medicine Volume 2 (In Two Volumes).. New York: Marcel Dekker; 1995. pp. 1020-36.

5. De Flora S, Wetterhahn KE. Mechanisms of chromium metabolism and genotoxicity. Life Chem Rep.1989;7(3):169-244.

6. De Flora S. Metabolic deactivation of mutagens in the Salmonel la-microsome test. Nature. 1978;271(5644):455-6.

7. De Flora S, Badolati GS, Serra D, Picciotto A, Magnolia MR, Savarino V. Circadian reduction of chromium in the gastric environment. Mutat Res. 1987;192(3):169-74.

8. De Flora S, Camoirano A, Bagnasco M, Bennicelli C, Corbett GE, Kerger BD. Estimates of the chromium(VI) reducing capacity in human body compartments as a mechanism for attenuating its potential toxicity and carcinogenicity. Carcinogenesis. 1997;18(3):531-7.

9. De Flora S. Threshold mechanisms and site specificity in chromium(VI) carcinogenesis. Carcinogenesis. 2000;21(4):533-41

10. Sugiyama M. Effects of vitamins on chromium(VI)-induced damage. Environ Health Perspect. 1991;92:63-70.

11. Sayato Y, Nakamuro K, Matsui S, Ando M. Metabolic fate of chromium compounds. I. Comparative behavior of chromium in rat administered with $\mathrm{Na} 251 \mathrm{CrO} 4$ and $51 \mathrm{CrCl} 3$. J Pharmacobiodyn. 1980;3(1):17-23.

12. Gray SJ, Sterling K. The tagging of red cells and plasma proteins with radioactive chromium. J Clin Invest.1950;29(12):1604-13.

13. Patlolla AK, Barnes C, Yedjou C, Velma VR, Tchounwou PB. Oxi- dative stress, DNA damage, and antioxidant enzyme activity in duced by hexavalent chromium in Sprague-Dawley rats. Environ Toxicol.2009;24(1):66-73.

14. Petrilli FL, De Flora S. Toxicity and mutagenicity of hexavalent chromium on Salmonella typhimurium. Appl Environ Microbiol. 1977;33(4):805-9.

15. Valko M, Rhodes CJ, Moncol J, Izakovic M, Mazur M. Free radicals, metals and antioxidants in oxidative stress-induced cancer. Chem Biol Interact. 2006;160(1):1-40.

16. Krysiak R, Zmuda W, Okopien B. The effect of ezetimibe, administered alone or in combination with simvastatin, on lymphocyte cytokine release in patients with elevated cholesterol levels. J Intern Med. 2012;271(1):32-42.

17. Jones PH, Davidson MH, Stein EA, Bays HE, McKenney JM, Miller E, et al. Comparison of the efficacy and safety of rosuvastatin versus atorvastatin, simvastatin, and pravastatin across doses (STELLAR* Trial). Am J Cardiol. 2003;92(2):152-60.

18. Shepherd J, Hunninghake DB, Barter P, McKenney JM, Hutchinson HG. Guidelines for lowering lipids to reduce coronary artery disease risk: a comparison of rosuvastatin with atorvastatin pravastatin, and simvastatin for achieving lipid-lowering goals. Am J Cardiol. 2003;91(5A):11C-7C.

19. Rader DJ, Davidson MH, Caplan RJ, Pears JS. Lipid and apolipoprotein ratios: association with coronary artery disease and effects of rosuvastatin compared with atorvastatin, pravastatin, and simvastatin. Am J Cardiol. 2003;91(5A):20C-3C

20. Hemmati AA, Nazari Z, Ranjbari N, Torfi A. Comparison of the preventive effect of vitamin $\mathrm{C}$ and $\mathrm{E}$ on hexavalent chromium induced pulmonary fibrosis in rat. Inflammopharmacology. 2008;16(4):195-7.

21. Ogungbenro K, Aarons L. A semi-mechanistic gastric emptying pharmacokinetic model for (13)C-octanoic acid: an evaluation using simulation. Eur J Pharm Sci. 2012;45(3):302-10.

22. Yagi K. Assay for blood plasma or serum. Methods Enzymol. 1984;105:328-31.

23. Chowdhury NJ, Misbahuddin M, Rahman MS. Corn extracts lower tissue arsenic level in rat. Bangladesh Med Res Counc Bull. 2009;35(1):21-5.

24. Curello S, Ceconi C, Cargnoni A, Cornacchiari A, Ferrari R, Albertini A. Improved procedure for determining glutathione in plasma as an index of myocardial oxidative stress. Clin Chem. 1987;33(8):1448-9.

25. Sai Ram M, Anju B, Pauline T, Dipti P, Kain AK, Mongia SS, et al. Effect of Kombucha tea on chromate(VI)-induced oxidative stress in albino rats. J Ethnopharmacol. 2000;71(1-2):235-40.

26. Geetha S, Sai Ram M, Mongia SS, Singh V, Ilavazhagan G, Sawhney RC. Evaluation of antioxidant activity of leaf extract of Seabuckthorn (Hippophae rhamnoides L.) on chromium(VI) induced oxidative stress in albino rats. J Ethnopharmacol. 2003;87(2 3):247-51.

27. Arivarasu NA, Priyamvada S, Mahmood R. Caffeic acid inhibits chromium(VI)-induced oxidative stress and changes in brush border membrane enzymes in rat intestine. Biol Trace Elem Res. 2012;148(2):209-15.

28. Soudani N, Sefi M, Ben Amara I, Boudawara T, Zeghal N. Protective effects of Selenium (Se) on Chromium (VI) induced nephrotoxicity in adult rats. Ecotoxicol Environ Saf. 2010;73(4):671-8.

29. Pruefer D, Scalia R, Lefer AM. Simvastatin inhibits leukocyteendothelial cell interactions and protects against inflammatory processes in normocholesterolemic rats. Arterioscler Thromb Vas Biol.1999;19(12):2894-900.

30. Shishehbor MH, Brennan ML, Aviles RJ, Fu X, Penn MS, Sprecher DL, et al. Statins promote potent systemic antioxidant effects through specific inflammatory pathways. Circulation. 2003;108(4):426-31.

31. Scalia R, Gooszen ME, Jones SP, Hoffmeyer M, Rimmer DM, 3rd Trocha SD, et al. Simvastatin exerts both anti-inflammatory and cardioprotective effects in apolipoprotein E-deficient mice. Circulation. 2001;103(21):2598-603.

32. Maheshwari RA, Sailor GU, Patel L, Balaraman R. Amelioration of cisplatin-induced nephrotoxicity by statins. Indian J Pharmacol. 2013;45(4):354-8. 
33. Jabbari M, Rostami Z, Jenabi A, Bahrami A, Mooraki A. Simvastatin ameliorates gentamicin-induced renal injury in rats. Saudi J Kidney Dis Transpl. 2011;22(6):1181-6.

34. Fouad AA, Albuali WH, Jresat I. Simvastatin treatment ameliorates injury of rat testes induced by cadmium toxicity. Biol Trace Elem Res. 2013;153(1-3):269-78.
35. Stoll LL, McCormick ML, Denning GM, Weintraub NL. Antioxidant effects of statins. Timely Top Med Cardiovasc Dis. 2005;9:E1.

36. Ramanjaneyulu SV, Trivedi PP, Kushwaha S, Vikram A, Jena GB. Protective role of atorvastatin against doxorubicin-induced cardiotoxicity and testicular toxicity in mice. J Physiol Biochem. 2013;69(3):513-25. 